\title{
The Simulation of Automotive Braking Energy Recovery System based on AMESim
}

\author{
Bin Li, Lan Tang \& Hao Jiang \\ Key Research Lab for Vehicle, Xi Hua University, Chengdu Sichuan, China
}

Keywords: Braking Energy Recovery; Hydraulic Pump/Motor ; Hydraulic Accumulator ; AMESim.

\begin{abstract}
Based on AMESim, this paper focuses on the modeling and simulation of a particular bus. Set-ting a certain speed for the bus, and then take braking. Through analyzing the process of braking energy recov-ery and launching of the bus, a series of simulation curves are obtained. And then, it is concluded that the influence of the filling pressure of the accumulator and the displacement of the hydraulic pump on the braking performance are similar, and the volume of the accumulator have less effect on the braking performance.
\end{abstract}

\section{Instruction}

Braking energy recovery is a form of energy efficient and environmentally friendly way of braking which is different from the traditional friction braking. It makes a part of the mechanical energy converted to other forms of energy, through the energy conversion device which connected to the drive axle. And then, the energy will be stored in an energy storage device. During the vehicle starting, acceleration, uphill, this part of energy as auxiliary power supply released and returned to drive axle. The working process of the braking energy recovery system itself is the process of the automobile braking deceleration, so the use of this system will reduce the use of traditional braking system. It is to say, the use of Braking Energy Recovery System can improve the power performance and fuel economy of the vehicle, and can reduce the emissions of pollutants and the wear and tear of the braking system.

\section{The amesim model of the BUS equipped with braking energy recovery system}

\section{Composition of the System}

The complete model consists of mechanical parts, hydraulic parts and signal control parts, as shown in Fig.1.

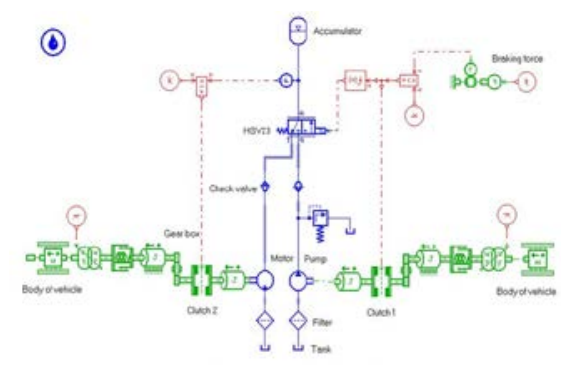

Figure 1. The complete AMESim model of the system

Mechanical parts include the clutch, gearbox, drive shaft, translation/rotation converters, body mass and the pedal force sensor, as shown in Fig.2.

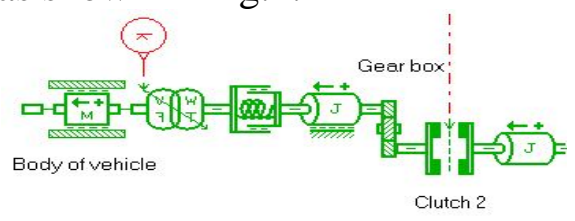

Figure 2. The AMESim model of mechanical parts

Hydraulic parts include one-way quantitative hydraulic pump/motor, two three-way reversing valve, hydraulic accumulator, overflow valve, Check valve, hydraulic circuit, filter, pressure sensor 
and fuel tank, as shown in Fig.3.

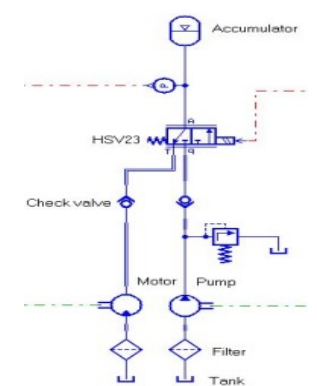

Figure 3. The AMESim model of hydraulic parts

Signal control parts include $\mathrm{x} / \mathrm{y}$ link, clutch control signal, the reversing valve control function, as shown in Fig.4.

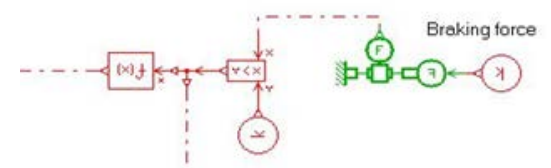

Figure 4. The AMESim model of signal control parts

\section{Operating principle of the System}

The $\mathrm{K}$ value of the Braking force model is used to simulate the brake pedal force. It is measured by force sensor and will be compared with the $\mathrm{K}$ value of $\mathrm{x} / \mathrm{y}$ link. The force of the brake pedal can be simplified as the two kinds of situations, which is the pedal force greater than zero $(\mathrm{K}>0)$, another kind of situation is pedal force equal to zero $(\mathrm{K}=0)$. When pedal force is greater than zero, the combination of the clutch, the conduction of the reversing valve's port $\mathrm{P}$ and port $\mathrm{A}$ and the shutting of the reversing valve's port $\mathrm{T}$, representative the breaking energy recovery system began to work. The parameters of the car can be set in the mechanical model, such as initial braking speed, quality. And then, the system has a little initial energy. This energy is passed on to the pump shaft of the hydraulic pump in the form of torque. When the hydraulic oil stored in the tank flows to the accumulator through the reversing valve's port $\mathrm{P}$ and port $\mathrm{A}$, the nitrogen stored in the accumulator is compressed. At the same time, the car's mechanical energy converted into hydraulic energy, and stored in the accumulator. The energy route is: the body--the drive shaft--transmission--the clutch1-hydraulic pump--check valve--reversing valve's port $\mathrm{P}$ and port A--the hydraulic accumulator. When the pedal force is equal to zero, the separation of the clutch1, the combination of the clutch2, the conduction of the reversing valve's port $A$ and port $T$ and the shutting of the reversing valve's port $\mathrm{P}$, simulate the car's started or accelerated condition. After the proper setting of the parameters of the accumulator, the hydraulic oil stored in the accumulator flows back to the fuel tank through the reversing valve's port $\mathrm{A}$ and port $\mathrm{T}$ and hydraulic motor. At this time the energy route is: the hydraulic accumulator--reversing valve's port A and port T--check valve--the hydraulic motor--the clutch--gearbox--the drive shaft--the body.

\section{Simulation and result analysis}

\section{Simulation of Braking Energy Recovery}

Because the bus is at a low speed running all the year round in the city, the braking original speed of the bus is set to $45 \mathrm{~km} / \mathrm{h}$ in the simulation. And setting the parameters of the bus as follows: the K value of Braking force to be positive (such as 10), the speed of Body of vehicle to be 45 $\mathrm{km} / \mathrm{h}$, the vehicle's running time to be $15 \mathrm{~s}$, the running type to be single run. The curves which describe the speed, the braking distance and the volume and gas pressure of the hydraulic accumulator changing over time are shown in the figures below. 


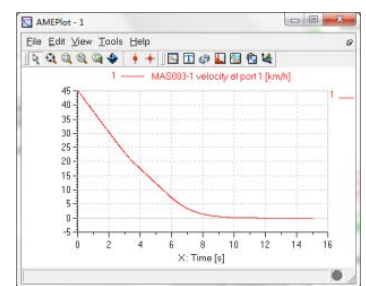

Figure 5. The speed changes over time

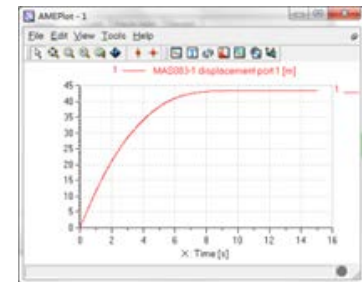

Figure 6. The braking distance changes over time

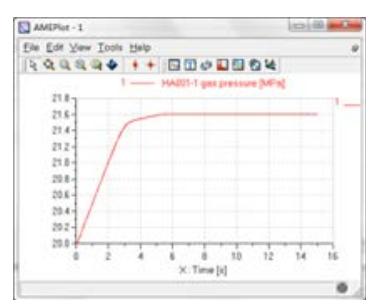

Figure 7. The gas pressure changes over time

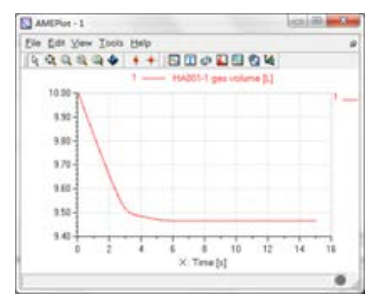

Figure 8. The volume changes over time

Through the analysis of the above four pictures, we can know that the braking time is roughly $10 \mathrm{~s}$, the braking distance is $43 \mathrm{~m}$ and the maximum of the gas pressure of the accumulator is 21.6039MPa under the braking model that braking force only provided by Braking Energy Recovery System . It is clear that the gas pressure increases sharply in the first 3s, and then the growth is slowing down. Finally, it reaches the maximum at the sixth seconds.

\section{Simulation of Energy loss}

The kinetic energy formula is:

$$
\mathrm{E}=0.5 \times \mathrm{m} v^{2}
$$

Changing the unit of the speed into $\mathrm{km} / \mathrm{h}, \mathrm{Eq} .2$ is obtained:

$\mathrm{E}=6.48 \times \mathrm{m} v^{2}$

Where, E: kinetic energy; m: quality; v: speed.

The simulation is conducted under the adiabatic condition, so the loss of the accumulator's energy is neglected. And on the basis of the pressure and flow of the accumulator's port, the accumulator's ability to store energy is calculated.

The Power formula is:

$$
\mathrm{P}=p Q
$$

Where, P: Power; $p$ : Pressure; Q: The rate of change of volume.

Changing the unit of the rate of change of volume into $\mathrm{L} / \mathrm{min}, \mathrm{Eq} .4$ is obtained:

$$
\mathrm{P}=6 \times 10^{4} p Q
$$

Through mathematical processing, the curve which describes the kinetic energy and the stored energy of the accumulator changing over time can be get on the basis of the above formulas. 


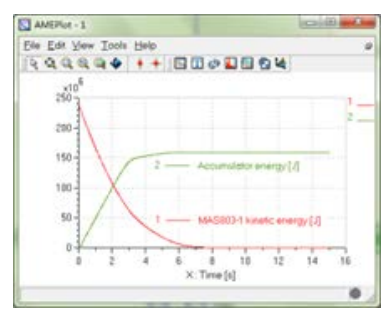

Figure 9.The kinetic energy and the stored energy of the accumulator change over time Analyzing the graph, it is clear that the bus's initial kinetic energy is $2.36 * 108 \mathrm{~J}$, and the stored energy of the accumulator eventually is $1.6 * 108 \mathrm{~J}$, so $32 \%$ of the energy is lost.

\section{Simulation of Starting}

The parameters of the bus are set as follows: the $\mathrm{K}$ value of Braking force to be zero, pressure of the accumulator to be $21.6039 \mathrm{MPa}$, the vehicle's running time to be $15 \mathrm{~s}$, the running type to be single run. And the curves which describe the gas pressure and volume of the hydraulic accumulator, speed and mileage changing over time are shown in the figures below.

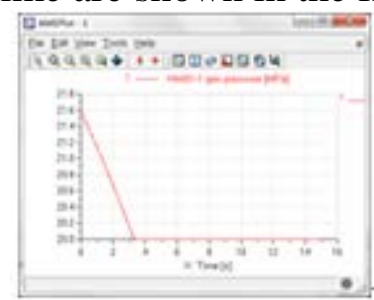

Figure.10 The gas pressure changes over time

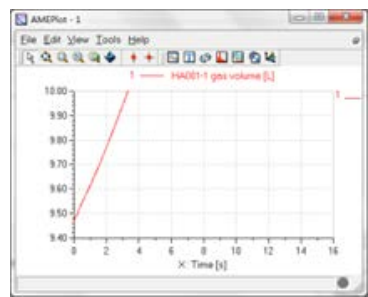

Figure.11 The volume changes over time

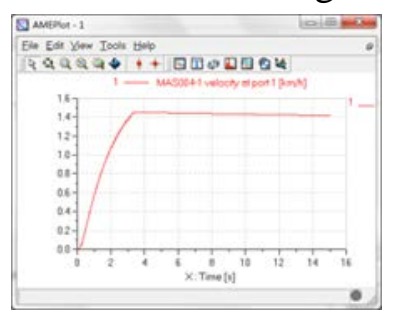

Figure.12 The speed changes over time

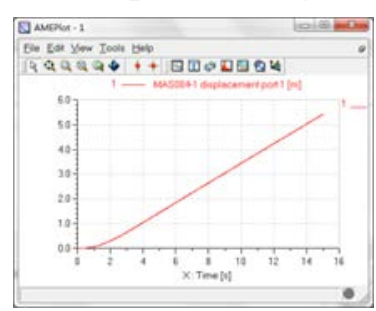

Figure.13 The mileage changes over time

Through the analysis of the above four pictures, we can find that the gas pressure of the accumulator declined from 21.6039MPa to 20MPa within 3.3s, and the volume of the accumulator rise from $9.4664 \mathrm{~L}$ to $10 \mathrm{~L}$ rapidly. $15 \mathrm{~s}$ later, the speed of the bus is accelerated to $1.45 \mathrm{~km} / \mathrm{h}$, and the mileage reaches $5.42 \mathrm{~m}$.

\section{Simulation of the Influence Factors to Braking Performance}

Braking performance parameters mainly include accumulator prefilled pressure, accumulator volume and displacement of hydraulic pump. Taking the braking time as the independent variable, this paper studies the influence of these parameters on the braking performance. 


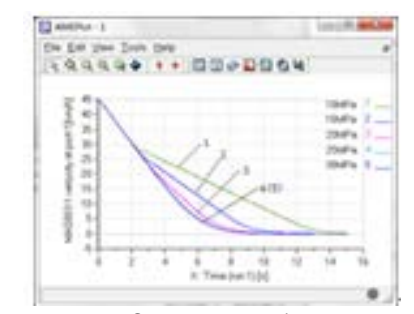

Figure.14 Influence of accumulator prefilled pressure

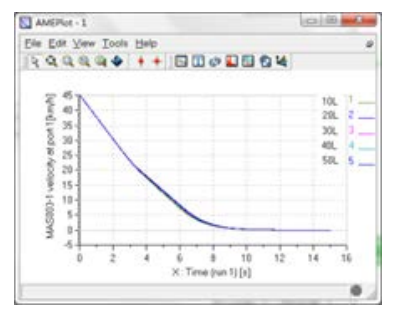

Figure.15 Influence of accumulator volume

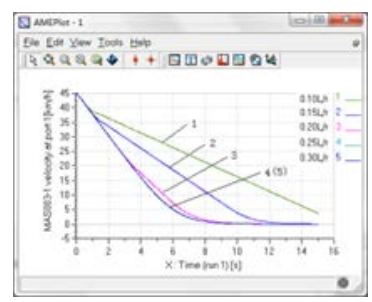

Figure.16 Influence of displacement of hydraulic pump

From the four graphs, it is clear that the influence of prefilled pressure of accumulator and displacement of hydraulic pump on braking time is similar. And it is greater than volume of accumulator. The braking time along with the increase of these two factors has a certain degree of reduced. But when the accumulator prefilled pressure more than 25MPa and hydraulic pump displacement exceed $0.25 \mathrm{~L} / \mathrm{r}$, the braking time no longer reduces.

\section{Conclusion}

In the system, the simulations of the braking and starting condition have been made. At the same time, the energy loss and the influence factors to braking performance also have been taken into consideration. However, some influence factors did idealized processing in the simulation. Such as, the energy loss of the accumulator, the hydraulic pump and mechanical transmission system is neglected. So results of the simulation show that the energy recovery rate is relatively high. In the simulation, the initial speed of the bus is $45 \mathrm{~km} / \mathrm{h}$. And the results show that $68 \%$ of the energy can be recycled, if the Braking Energy Recovery System is used during the braking. This will increase the efficiency of energy utilization, and then the bus will have a good fuel economy.

\section{Acknowledgements}

The support of the key subject project for vehicle engineering of Sichuan (SZD0410), Automobile Engineering Laboratory of Sichuan (SGXZD9902-10-1), Graduate Innovation Fund of Xihua University (YCJJ2014097) are acknowledged.

\section{REFERENCES}

1. Zhengqian Wu, Summary of the Motor Regenerative Braking Energy Recovery System, The theory of science, 2010.

2. Ziying Zhang, Baocheng Zhang, Vehicle Braking Energy Recycling Technology Research, Energy Saving Technology, 2010, 28 (3).

3. Weigang Zhang, Xiaolin Zhu, Hydraulic technology in hybrid electric vehicle energy saving applications, Machine with hydraulic, 2006 (6): 144-146. 
4. Keli Xing, Yang Li, Xiajie Jin, Shaocheng Jiang, Zainong Dai, Shunxiang Zhang, Study of the City Bus Braking Energy Regeneration System and the Experiment, The Hydraulic and Pneumatic, 2010 (9).

5. Jianguo Xi, Zhenping Gao, Jie Chen, Junfeng Chao, Model of the Braking Energy Regeneration System based on AMESim, Mechanical design and Manufacture, 2010 (9), 5.

6. Tianhao Liu, Haichao Liu, Changhong Zhu, AMESim Simulation of Vehicle Braking Energy Recovery System with Hydraulic Energy storage type, Machine with hydraulic, 2011, 33 (3) 6. 